\title{
Estimation of genetic parameters and trends for energy- corrected 305-d milk yield in Iranian Holsteins
}

\author{
Navid Ghavi Hossein-Zadeh \\ Department of Animal Science, Faculty of Agricultural Sciences, University of Guilan, Rasht, Iran
}

\begin{abstract}
Calving records from the Animal Breeding Centre of Iran collected from January 1995 to December 2007 and comprising 217973 calving events of Holsteins from 704 dairy herds were analysed using univariate and bivariate linear animal models to estimate heritabilities and genetic correlations for energy-corrected 305-d milk yield (ECM) in the first three lactations of Holstein cows. Genetic trends were obtained by regressing yearly mean estimates of breeding values on calving year. Average ECM increased from parity 1 through parity 3 . Estimates of heritabilities were from 0.14 to 0.21 for ECM and decreased over the parities. The greatest genetic correlations were between ECM2 and ECM3 (0.96), and the greatest phenotypic correlations were between ECM1 and ECM2 (0.57) and ECM2 and ECM3 (0.57). The high and positive genetic correlations between ECM traits at different lactations are evidence for common genetic and physiological mechanism controlling these traits. There were positive and increasing phenotypic and genetic trends for ECM over the years $(P<0.001)$. Higher heritability of the ECM in the first parity along with the high genetic correlations between first-lactation ECM with these traits in other lactations shows that higher potential exists for selecting animals for ECM based on their first parity records.
\end{abstract}

Keywords: heritability, genetic correlation, dairy cow, genetic progress, milk production

\section{Introduction}

Milk production per cow has been considerably improved within the last decades, but the increase in milk yield has been accompanied by a higher occurrence of health and fertility problems worldwide (Pryce et al. 1997). Dairy cows are considered less robust than in the past (Gengler \& Soyeurt 2010). Antagonistic relationships between production, health and fitness traits have given cause for concern, not only because the efficiency of production is reduced by higher incidences of diseases, but also due to animal welfare issues (Conington et al. 2010).

The negative energy balance in early lactation is considered to play a decisive role in this context. Most of the health problems in highly selected dairy cows occur at the beginning of lactation and have been related to the extent and duration of the energy deficit post partum (Collard et al. 2000, Ingvartsen \& Andersen 2000). Cows require sufficient energy intake to support their physiological functions, namely to produce milk and grow while reproducing and staying healthy (Banos et al. 2006). However, selection for milk traits has resulted in a partial shift of available energy towards milk production at the cost of other biological pathways (Collard et al. 2000). If daily energy requirements exceed daily energy availability, 
body fat is used as a temporary energy buffer (Banos et al. 2005). This is a normal mammalian physiological process (Pond \& Newsholme 1999), but excessive mobilisation due to a severe energy deficit seems to affect the constitution of the cow (Collard et al. 2000) and leads to metabolic stress (Pryce \& Løvendahl 1999). As a consequence, cows in a prolonged negative energy balance often fail to maintain functional fitness. The severity of the energy deficit in early lactation is certainly influenced by the diet offered (Webb et al. 1999). However, Ingvartsen \& Friggens (2005) investigated the metabolic status of cows consuming the same diet and producing a similar amount of milk and found substantial between-cow variation in the metabolic status. Similarly, Coffey et al. (2004) demonstrated that distinct genetic lines responded differently to a range of diets and differed in the time taken to return to a positive energy balance.

There is a general agreement that energy balance should be included into future breeding programs, but direct measurements are costly and difficult to be implemented in practice (Hüttmann et al. 2009). Thus, there is a large interest in low cost traits describing the energy status in an appropriate way. Energy corrected 305-d milk yield (ECM) accounts for the true protein content of milk and determines the amount of energy in the milk based upon milk, fat and protein. The ECM could be considered as criterion for the energy status of dairy cows, but although estimates of genetic parameters and trends for milk traits were reported in previous study (Ghavi Hossein-Zadeh 2011), estimation of the genetic parameters and trends for ECM has rarely been investigated until now. Therefore, the primary objective of this study was to study the genetic parameters of ECM and the other objective was to estimate the genetic trends for ECM in the first three lactations of Iranian Holsteins.

\section{Material and methods}

\section{Data}

Calving records from the Animal Breeding Centre of Iran, collected from January 1995 to December 2007 and comprising 217973 calving events of Holsteins from 704 dairy herds were included in the data set. The herds used in this study are among the purebred Holsteins which are managed under conditions similar to most other developed countries and are under official performance and pedigree recording. Information for individual calving events, including herd identification, cow identification, calving date, parity, calving age, 305-d milk yield, 305-d milk fat yield, 305-d milk protein of yield and 305-d fat and protein percentages of milk were included in the data set. The pedigree information used in this study was extracted from the database used for the national genetic evaluation of dairy traits in Iran, which had been provided by the Animal Breeding Centre of Iran and reported by Ghavi Hossein-Zadeh et al. (2009) in previous study. The data were screened several times and defective and doubtful data were deleted. Outliers and out of range productive records were deleted from the analyses. Therefore, milk production records lower than $2500 \mathrm{~kg}$ and greater than $12500 \mathrm{~kg}$ were removed from the dataset. Records were also eliminated if no registration number was present for a given cow. Ages at calving were required to be between 20 and 40, 28 and 49, and 40 and 68 months in lactations one, two, and three, respectively. Months of birth were grouped into four seasons: January through March (winter), April through June (spring), July through September (summer), and October through December (fall). ECM was defined as 
(Ekern 1991): $305-d$ milk yield $\times(0.01+0.122 \times$ mean fat percentage $+0.077 \times$ mean protein percentage $)=$ kilograms of ECM.

\section{Statistical models of analysis}

The following univariate animal model was fitted to estimate variance components and heritabilities separately for ECM in the first three lactations of Holstein cows:

$$
y_{i j k l}=\mu+a_{i}+\text { hys }_{j}+b_{1 k} \text { Age }_{k}+e_{i j k l}
$$

where $y_{i j k l}$ was single observation of ECM affected by random additive genetic effect of animal $i\left(a_{i}\right)$ in fixed effects of herd-year-season of calving $j\left(h_{y s}\right)$, and the random effect of residual error $\left(e_{i j k l}\right)$. Also, $b_{1 k}$ was regression coefficient on the first order for age at calving $\left(\right.$ Age $\left._{k}\right)$.

Bivariate or pairwise animal models were used to estimate genetic and phenotypic correlations between first-, second-, and third-lactation ECM traits. The models applied in pair-wise analyses were the same as those fitted for the genetic analysis of each trait in the univariate analyses and were, in matrix notation, as follows:

$$
\left[\begin{array}{l}
y_{1} \\
y_{2}
\end{array}\right]=\left[\begin{array}{ll}
X_{1} & 0 \\
0 & X_{2}
\end{array}\right]\left[\begin{array}{l}
b_{1} \\
b_{2}
\end{array}\right]+\left[\begin{array}{ll}
z_{1} & 0 \\
0 & Z_{2}
\end{array}\right]\left[\begin{array}{l}
u_{1} \\
u_{2}
\end{array}\right]+\left[\begin{array}{l}
e_{2} \\
e_{2}
\end{array}\right]
$$

where $y_{1}$ and $y_{2}$ were the vectors of observations for ECM in different lactations; $\boldsymbol{b}_{1}$ and $\boldsymbol{b}_{2}$ denoted the fixed effects in the models with association matrices $X_{1}$ and $X_{2} ; u_{1}$ and $\boldsymbol{u}_{2}$ were the vectors of direct genetic effects with the incidence matrices $Z_{1}$ and $Z_{2}$; and $e_{1}$ and $e_{2}$ denoted the vectors of residual effects.

\section{Genetic analyses}

The linear univariate and bivariate animal model analyses were run using a restricted maximum likelihood method and average information algorithm (AIREML) of the MATVEC program (Wang et al. 2001) to obtain heritabilities and genetic correlations of ECM in first, second, and third lactations. Genetic trends were obtained by regressing yearly mean estimates of breeding values on year of calving. Also, phenotypic trends were estimated using the linear regression of average phenotypic values on calving year.

\section{Results and discussion}

Summary statistics for ECM are shown in Table 1. Average ECM increased from parity 1 through parity 3. Increasing phenotypic means of ECM over the parities suggest that parity could impact positively on the milk energy outputs in dairy cows. It was shown that the greater ECM requires greater glucose and amino acids. Glucose is essential to provide 1) NADPH for de novo milk fat synthesis and 2) ATP for protein synthesis from amino acids (Mayes 2000).

Estimates of heritabilities, genetic and phenotypic correlations for ECM in the first three lactations of Holstein cows are presented in Table 2. Estimates of heritabilities were from 0.14 to 0.21 for ECM and decreased over the parities. Effective breeding programs depend on the accuracy of genetic and phenotypic parameter estimates, which include heritability 
and correlation between traits. Estimates of heritabilities for ECM were generally low. The low estimates of heritability for ECM obtained in this study could be attributable to the high phenotypic variance arising from large environmental variation. This therefore implies that much of the improvement in these traits could be attained by improvement of production environment rather than selection, as suggested by other authors (van der Westhuizen et al. 2001). There were no estimates of heritabilities for energy-corrected 305-d milk yield in the literature, but generally consistent with the current results, Hüttmann et al. (2009) reported the average heritability of 0.23 for daily ECM in the first lactation Holstein cows and Liinamo et al. (2010) reported the average heritability of 0.25 for daily ECM in Nordic Red dairy cattle.

Table 1

Summary statistics for energy corrected 305-d milk yield in the first three lactations of Iranian Holsteins from 1995 to 2007

\begin{tabular}{lcccc}
\hline Trait & Number of observations & Mean & Standard deviation & Coefficient of variation, \% \\
\hline ECM1, kg & 92187 & 4523.3 & 867.8 & 19.2 \\
ECM2, kg & 74708 & 4953.3 & 1073.1 & 21.7 \\
ECM3, kg & 51078 & 5093.7 & 1161.3 & 22.8 \\
\hline
\end{tabular}

ECM1: 1st lactation energy corrected 305-d milk yield, ECM2: 2nd lactation energy corrected 305-d milk yield, ECM3: 3 rd lactation energy corrected 305-d milk yield

Table 2

Estimates of heritabilities (in bold on diagonal), genetic correlations (above the diagonal) and phenotypic correlations (below the diagonal) for energy corrected 305-d milk yield in the first three lactations of Iranian Holsteins (standard error of estimates are in brackets)

\begin{tabular}{llll}
\hline Trait & ECM1 & $\begin{array}{l}\text { Trait } \\
\text { ECM2 }\end{array}$ & ECM3 \\
\hline ECM1 & $\mathbf{0 . 2 1 ( \mathbf { 0 . 0 1 ) }}$ & 0.93 & 0.82 \\
ECM2 & 0.57 & $\mathbf{0 . 1 9 ( 0 . 0 1 )}$ & 0.96 \\
ECM3 & 0.45 & 0.57 & $\mathbf{0 . 1 4}(\mathbf{0 . 0 1 )}$
\end{tabular}

ECM1: 1st lactation energy corrected 305-d milk yield, ECM2: 2nd lactation energy corrected 305-d milk yield, ECM3: 3rd lactation energy corrected 305-d milk yield

Table 3

Estimates of genetic and phenotypic trends ( \pm SE) for energy corrected $305-d$ milk yield $(E C M)$ in the first three lactations of Iranian Holsteins*

\begin{tabular}{lrl}
\hline Trait & & Trend \\
& Phenotypic & Genetic \\
\hline ECM1 & $82.95 \pm 0.89$ & $7.79 \pm 0.34$ \\
ECM2 & $115.12 \pm 1.23$ & $8.92 \pm 0.24$ \\
ECM3 & $120.66 \pm 1.63$ & $5.97 \pm 0.25$ \\
\hline
\end{tabular}

ECM1: 1st lactation energy corrected 305-d milk yield, ECM2: 2nd lactation energy corrected 305-d milk yield, ECM3: 3rd lactation energy corrected 305-d milk yield, ${ }^{*}$ All estimates were significant at $P<0.001$.

The greatest genetic correlations were between ECM2 and ECM3 (0.96), and the greatest phenotypic correlations were between ECM1 and ECM2 (0.57) and ECM2 and ECM3 (0.57). Estimates of genetic and phenotypic correlations are important in genetic improvement programmes since they indicate the extent to which one trait will genetically and 
phenotypically change if a correlated trait is improved. Different traits may be influenced by the same genes, implying that expression of one trait depends on the other. The high and positive genetic correlations between ECM traits at different lactations are evidence for common genetic and physiological mechanism controlling these traits. Also, positive and high genetic correlation between the traits under study suggesting that selection of dairy cows in favour of ECM in one lactation would also improve ECM in other lactation. Higher heritability of the ECM in the first parity along with the high genetic correlations between first-lactation ECM with these traits in other lactations shows that higher potential exists for selecting animals for ECM based on their first parity records. This is an advantage due to reduced generation interval.

Estimates of genetic and phenotypic trends for ECM in Iranian Holsteins are shown in Table 3. There were positive and increasing phenotypic and genetic trends for ECM over the years $(P<0.001)$. Phenotypic trends and mean estimated breeding values for ECM by year of calving are shown in Figures 1 to 2, respectively. Phenotypic means of ECM1, ECM2 and ECM3 increased consistently from 1995 to 2006 (Figure 1). There were decreasing trends for the mean estimated breeding values of ECM1, ECM2 and ECM3 from 1995 to 1998, 1995 to 2000 and 1995 to 2001, respectively. But, there were increasing trends for the mean estimated breeding values of first-, second- and third-lactation ECM from 1998, 2000 and 2001 onwards, respectively (Figure 2). There were no published reports of genetic trends for ECM in dairy cows, but similar to this study, Oltenacu \& Algers (2005) reported the ECM yield for Swedish dairy cows increased from 4200 to $9000 \mathrm{~kg}$ between 1957 and 2003. Overall, the positive genetic trend in ECM mostly owing to the effective use of artificial insemination (Al), progeny testing, and intense selection of bulls. Also, this increasing trend for ECM in this study indicated that Iranian dairy producers were successful in choosing progressively better semen and sires from imported and local sources over the years.

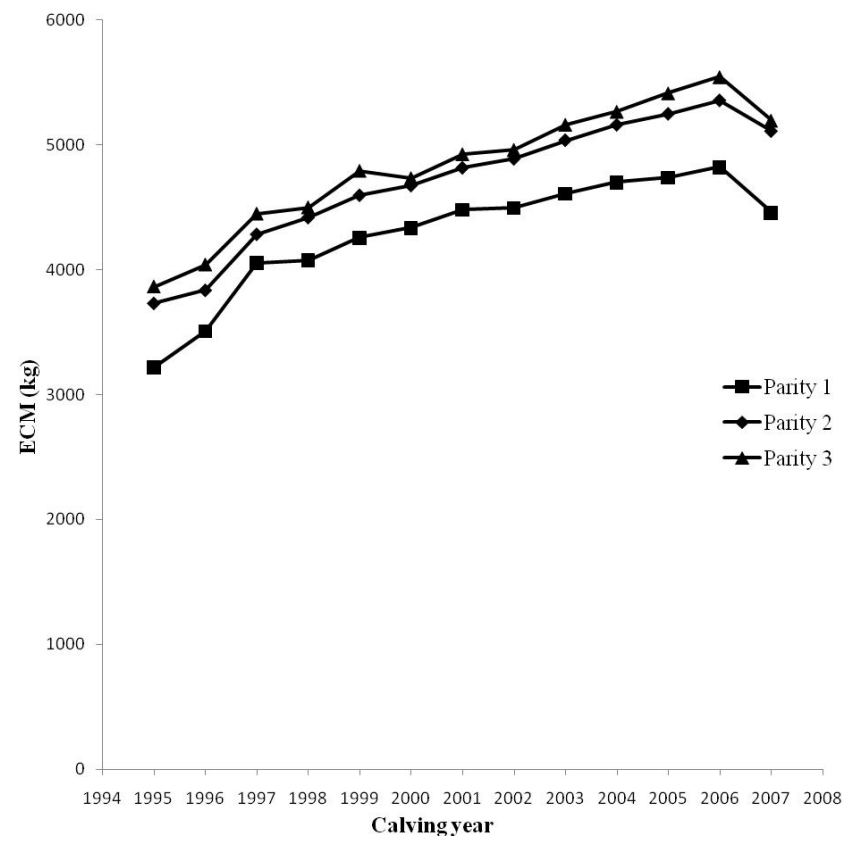

Figure 1

Phenotypic means of energy corrected 305-d milk yield by year of calving and parity 


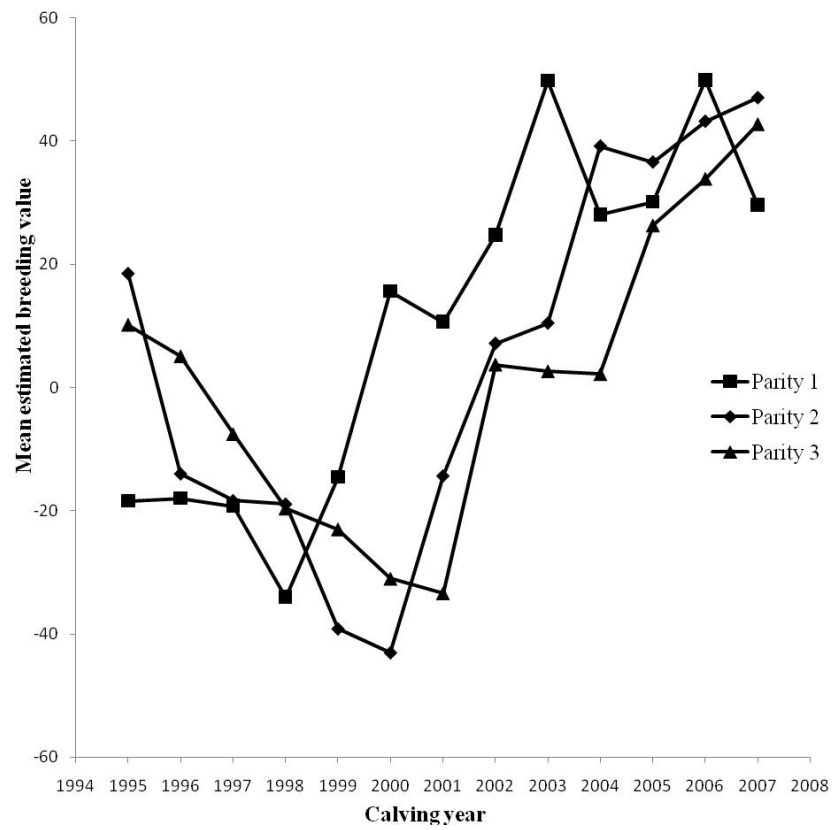

Figure 2

Mean estimated breeding values for energy corrected 305-d milk yield by year of calving and parity

In conclusions, estimates of heritabilities for ECM were generally low in this study. The high and positive genetic correlations between ECM traits at different lactations are evidence for common genetic and physiological mechanism controlling these traits. There were positive and increasing phenotypic and genetic trends for ECM over the years. Higher heritability of the ECM in the first parity along with the high genetic correlations between first-lactation ECM with these traits in other lactations shows that higher potential exists for selecting animals for ECM based on their first parity records. This is an advantage due to reduced generation interval and increased genetic progress in selection programs.

\section{References}

Banos G, Coffey MP, Brotherstone S (2005) Modeling daily energy balance of dairy cows in the first three lactations. J Dairy Sci 88, 2226-2237

Banos G, Coffey MP, Wall E, Brotherstone S (2006) Genetic relationship between first-lactation body energy and later-life udder health in dairy cattle. J Dairy Sci 89, 2222-2232

Coffey MP, Simm G, Oldham JD, Hill WG, Brotherstone S (2004) Genotype and diet effects on energy balance in the first three lactations of dairy cows. J Dairy Sci 87, 4318-4326

Collard BL, Boettcher PJ, Dekkers JCM, Petitclerc D, Schaeffer LR (2000) Relationships between energy balance and health traits of dairy cattle in early lactation. J Dairy Sci 83, 2683-2690

Conington J, Gibbons J, Haskell MJ, Bünger L (2010) The use of breeding to improve animal welfare. Proc. 9th World Congress on Genetics Applied to Livestock Production, August 2010, Leipzig, Germany

Ekern A (1991) A new system of energy evaluation of food for ruminants. Nor Landbruksforsk 5, 273-276

Gengler N, Soyeurt H (2010) Interest, recording and possible use of new phenotypes from fine milk composition. Proc. 9th World Congress on Genetics Applied to Livestock Production, August 2010, Leipzig, Germany

Ghavi Hossein-Zadeh N (2011) Genetic and phenotypic trends for age at first calving and milk yield and compositions in Holstein dairy cows. Arch Tierz 54, 338-347 
Ghavi Hossein-Zadeh N, Nejati-Javaremi A, Miraei-Ashtiani SR, Kohram H (2009) Estimation of variance components and genetic trends for twinning rate in Holstein dairy cattle of Iran. J Dairy Sci 92, 3411-3421

Hüttmann H, Stamer E, Junge W, Thaller G, Kalm E (2009) Analysis of feed intake and energy balance of highyielding first lactating Holstein cows with fixed and random regression models. Animal 3, 181-188

Ingvartsen KL, Andersen JB (2000) Integration of metabolism and intake regulation: a review focusing on periparturient animals. J Dairy Sci 83, 1573-1597

Ingvartsen KL, Friggens NC (2005) To what extent do variabilities in hormones, metabolites and energy intake explain variability in milk yield? Domest Anim Endocrinol 29, 294-304

Liinamo AE, Mäntysaari P, Mäntysaari EA (2010) Genetic parameters for feed intake, production and extent of negative energy balance in Nordic Red dairy cattle. Proc. 9th World Congress on Genetics Applied to Livestock Production, August 2010, Leipzig, Germany

Mayes PA (2000) Oxidation of fatty acids: Ketogenesis. In: Murray RK, Granner DK, Mayes PA, Rodwell VW (eds.) Harper's Biochemistry. 25th ed. Appleton and Lange, Stamford, CT, USA, 238-249

Oltenacu PA, Algers B (2005) Selection for increased production and the welfare of dairy cows; are new breeding goals needed? Ambio 34, 311-315

Pond CM, Newsholme EA (1999) Coping with metabolic stress in wild and domesticated animals. In: Oldham JD, Simm G, Groen AF, Nielsen BL, Pryce JE, Lawrence TLJ (eds.) Metabolic stress in dairy cows. British Society of Animal Science, Occasional Publication 24, 9-20

Pryce JE, Veerkamp RF, Thompson R, Hill WG, Simm G (1997) Genetic aspects of common health disorders and measures of fertility in Holstein Friesian dairy cattle. Anim Sci 65, 353-360

Pryce JE, Løvendahl P (1999) Options to reduce vulnerability to metabolic stress by genetic selection. In: Oldham JD, Simm G, Groen AF, Nielsen BL, Pryce JE, Lawrence TLJ (eds.) Metabolic stress in dairy cows. British Society of Animal Science, Occasional Publication 24, 119-127

Van der Westhuizen RR, Schoeman SJ, Jordaan GF, van Wyk JB (2001) Genetic parameters for reproductive traits in a beef cattle herd estimated using multitrait analysis. South Afric J Anim Sci 31, 41-48

Wang T, Fernando Rl, Kachman DS (2001) MATVEC user's guide. Univ Nebraska, Lincoln, NE, USA

Webb R, Garnsworthy PC, Gong JG, Robinson RS, Wathes DC (1999) Consequences for reproductive function of metabolic adaption to load. In: Oldham JD, Simm G, Groen AF, Nielsen BL, Pryce JE, Lawrence TLJ (eds.) Metabolic stress in dairy cows. British Society of Animal Science, Occasional Publication 24, 99-112

Received 23 September 2011, accepted 20 March 2012.

Corresponding author:

Navid Ghavi Hossein-Zadeh

email: nhosseinzadeh@guilan.ac.ir or navid.hosseinzadeh@gmail.com

Department of Animal Science, Faculty of Agricultural Sciences, University of Guilan, Rasht, Iran, P. O. Box: 41635-1314 